\title{
RSP Revisitada As mulheres nos altos escalões da administração pública no Brasil
}

Carmen Barroso*

Texto publicado na RSP, ano 43, 116(3), jul./out.,1988

\begin{abstract}
A situação das mulheres na administração pública brasileira, as discriminações que sofrem e as dificuldades que enfrentam para atingirem os altos escalões da burocracia estatal foram analisadas pela professora Carmen Lucia de Melo Barroso em trabalho apresentado em janeiro de 1987 na Inter-regional Workshop on Career Development of Managerial Women, ocorrida em Bangkok, e que a Revista do Serviço Público republica nesta edição. A luta das mulheres brasileiras pela ocupação de postos de comando na administração pública e as pressões psicológicas a que são submetidas foram corroboradas pelos dados contidos na pesquisa inédita na época sobre o processo de contratação, demissão e desenvolvimento da carreira dos executivos brasileiros, divulgada no dia 2 de dezembro de 1986, em São Paulo, pela agência de empregos Catho - Thomas Case. Pela pesquisa realizada no período, apenas $4 \%$ dos executivos brasileiros eram mulheres, sendo que $45 \%$ desse total de mulheres estavam concentrados na área de Recursos Humanos. Quase 30 anos depois, é fato que a atuação feminina no mercado de trabalho se ampliou, porém muitos dos desafios apresentados no artigo ainda persistem. No Poder Executivo Federal, de acordo com dados do Boletim Estatístico de Pessoal no 214, de fevereiro de 2014, o percentual de cargos de Direção e Assessoramento Superior (DAS) dos dois níveis mais altos - DAS 5 e 6 - ocupados por servidoras é de $28 \%$ e $19 \%$, respectivamente. Após anos de emancipação feminina e de luta pela igualdade de direitos, a balança de distribuição de cargos, funções e gratificações no serviço público brasileiro ainda pende para o lado masculino.
\end{abstract}

\footnotetext{
* Agradecimentos especiais à colaboração de Míriam Brizzocchi, Andreia Brunstein, Tina Amado, Mayra Soares, Maria Helena Coelho, Isolina R. S. Figueiredo, Adriana Gragnani, Leda do Nascimento, Ana Maria S. Teixeira, Tereza Ferraz, Eny M. Maya e Santamaria Silveira.
} 
Até meados do século XX o Estado brasileiro se caracterizava por uma política relativamente não intervencionista na área econômica e com pouco investimento nos serviços sociais. Conseqüentemente, a burocracia estatal era bastante reduzida e permaneceu assim até a década de 1930 quando a crise econômica mundial joga o país na trilha do desenvolvimento industrial através da substituição de importações e o Estado passa a ser um agente ativo, aumentando o seu poder e sua máquina burocrática. Vieira da Cunha $(1963$, p. 112, 114) descreve esse período: "Enquanto em 1920 havia 6 funcionários públicos para cada mil habitantes, esse número sobe para 12 em 1940... Há um fortalecimento da burocracia civil e militar no país como um todo. Isso reflete a transição de um país predominantemente rural para um país com características urbanas e industriais. É o fim do poder absoluto dos senhores de terra, sustentados por um Estado débil e pequeno. É o crescimento de uma organização política, se não a nível nacional, pelo menos a nível estadual".

Nas últimas cinco décadas, a máquina do Estado manteve um ritmo constante de crescimento acelerado, inclusive com a criação de muitas empresas estatais, especialmente nas áreas de infra-estrutura e indústria pesada. Ao lado desta participação crescente nas atividades produtivas, o Estado também expandiu e diversificou os tipos de serviço que presta, especialmente nas áreas de seguridade social, educação e saúde. O resultado é que a relação entre as despesas governamentais (nos três níveis - federal, estadual e municipal, incluindo-se as empresas estatais) e o PIB (produto interno bruto) subiu de 12,5\% em 1920 para 32,2\% em 1969 (BAER et al., 1973).

O sistema público é, pois, um empregador importante no Brasil. Isso ocorre em todas as regiões do país, embora respondendo a diferentes necessidades e, portanto, apresentando características diferentes em cada região. Segundo Vieira da Cunha, a expansão da burocracia estatal no Sul corresponde a uma maior eficiência na participação do Estado em uma economia cada vez mais complexa e desenvolvida, enquanto no Nordeste, onde o nível total de desenvolvimento é muito mais baixo, essa expansão busca acomodar as demandas de uma classe média urbana para quem o setor privado não é capaz de oferecer empregos em número suficiente, acarretando o empreguismo. Além disso, a exigência real dos empregos é tão pequena e os salários tão baixos que, especialmente os funcionários públicos de níveis mais elevados podem facilmente manter dois ou mais empregos ao mesmo tempo (GIFFIN, 1979); uma prática bastante comum, embora ilegal.

Dentro do que já foi chamado de "privatização da ordem pública", o emprego governamental é "tradicionalmente um meio de pagamento de débitos pessoais e de benefício de dependentes". Pode-se considerar que as preocupações familiares e interpessoais dominam a natureza das relações dentro das estruturas do emprego público, embora não sejam sua exclusividade (GIFFIN, p. 172). 
Paralelamente e de forma simultânea a esta política clientelista, passa a existir um sistema universal de promoção e acesso através da avaliação objetiva de méritos para os cargos inferiores, a partir de 1938, quando foi aprovado o Estatuto do Serviço Público. Desde 1918, os funcionários públicos reivindicavam o fim do favoritismo e da insegurança no emprego, mas a lei só foi promulgada quando ganharam reconhecimento político através de sua participação na Revolução de 1932 (VIEIRA DA CUNHA, 1963, p. 64).

Uma vez que a grande maioria da população brasileira permanece marginalizada tanto do sistema educacional quanto das oportunidades de emprego, os empregos da administração pública gozam de uma posição relativamente privilegiada, embora para os indivíduos com educação universitária - especialmente nas regiões mais desenvolvidas do país - o emprego público tenha se tornado uma alternativa pouco desejável, a ser evitada sempre que possível, como mostra Gouveia (1972). Mesmo durante a ditadura militar das décadas de 1960 e 1970, o período em que os analistas falam do surgimento de uma nova tecnocracia, Martins (1974) aponta que engenheiros, economistas, cientistas sociais, profissionais da área de ciências naturais, tendiam a acreditar que cientistas e técnicos perdem sua autonomia crítica e não são capazes de implementar seus projetos e ideais quando passam a trabalhar para o governo.

\section{As mulheres na administração pública}

O fim da discriminação sexual no emprego público estava na ordem do dia para as professoras e esposas de funcionários públicos que fundaram o Partido Republicano Feminino, nos idos de 1910. Por volta de 1920 alguns postos públicos importantes foram conquistados pelas mulheres, às vezes através de concursos abertos aos quais podiam se candidatar depois de recorrer à justiça. Bertha Lutz, a mais famosa líder brasileira da campanha pelo voto feminino, foi contratada como bióloga pelo Museu Nacional em 1919. As mulheres brasileiras conquistaram o direito de voto em 1932, depois de uma campanha que reunia mulheres profissionais, trabalhadoras de escritório, funcionárias públicas e enfermeiras, mas não trabalhadoras fabris. Essa vitória teve uma vida curta, pois em 1937 um golpe bania as eleições e excluía as mulheres da diplomacia e outros postos governamentais aos quais tinham sido admitidas recentemente (HAHNER, 1981).

O Censo do serviço público federal, de 1938, entretanto, registrou $8,8 \%$ de mulheres. Essa percentagem subiu para 20,6\% em 1958 quando foram publicados dados separados para os cargos efetivos (26,4\% mulheres) e não efetivos (15,9\%) (Vieira da Cunha, 1963). A vantagem relativa das mulheres em relação aos cargos efetivos se deve provavelmente à lei de 1938 que estabelecia que tais postos deviam ser preenchidos através de concursos abertos e testes anônimos. 
De fato, a administração pública se tornou cada vez mais uma fonte importante de emprego para as mulheres, como se pode ver na Tabela 1, apesar do fato de que a percentagem apresentada nessa tabela subestima o peso da administração pública, principalmente porque os professores da rede pública, os trabalhadores da saúde e serviços sociais estão computados na categoria de "atividades sociais". Levando-se em consideração que uma grande proporção desses trabalhadores são empregados pelo Estado ${ }^{1}$, e que desses a maioria são mulheres (ver Tabela 2), é claro que tem uma importância maior para as mulheres do que para os homens, e que essa diferença relativa vem crescendo através dos anos. Isso se deve, provavelmente, a uma conjunção de quatro fatores que se reforçam mutuamente: o fato do Estado prover serviços tradicionalmente desempenhados pelas mulheres dentro das famílias e o reforço ideológico da imagem que marca estas tarefas como "trabalho feminino"; a crescente deterioração dos salários dos servidores públicos, tornando-as cada vez menos desejáveis para os homens, exceto nos casos de postos mais elevados e em algumas empresas estatais; a menor exigência característica dos empregos públicos, tornandoos mais compatíveis com a dupla jornada das mulheres, uma vez que o trabalho doméstico e o cuidado com as crianças não são compartilhados pelos homens em casa; e a atitude menos discriminatória do Estado nas contratações, sendo supostamente ele o guardião da implementação de leis antidiscriminatórias no setor privado.

Tabela 1: Distribuição ocupacional por sexo e ramo de atividade Brasil (1950/1985)

\begin{tabular}{|c|c|c|c|c|c|c|c|c|c|c|}
\hline \multirow{2}{*}{$\begin{array}{l}\text { Setor e ramos de } \\
\text { atividade }\end{array}$} & \multicolumn{2}{|c|}{1950} & \multicolumn{2}{|c|}{1960} & \multicolumn{2}{|c|}{1970} & \multicolumn{2}{|c|}{1980} & \multicolumn{2}{|c|}{$1985^{1}$} \\
\hline & Masc. & Fem. & Masc. & Fem. & Masc. & Fem. & Masc. & Fem. & Masc. & Fem. \\
\hline Setor primário & 65.0 & 30.2 & 59.2 & 30.0 & 50.6 & 20.4 & 35.2 & 13.6 & 33.6 & 18.4 \\
\hline $\begin{array}{l}\text { Setor } \\
\text { secundário }\end{array}$ & 18.9 & 15.7 & 13.1 & 12.2 & 19.9 & 10.3 & 28.6 & 15.1 & 27.0 & 12.4 \\
\hline Setor terciário & 21.1 & 51.1 & 27.7 & 57.8 & 29.5 & 69.3 & 36.2 & 71.3 & 39.4 & 69.1 \\
\hline Comércio & 6.9 & 3.5 & 7.0 & 4.2 & 8.0 & 6.0 & 9.3 & 9.4 & 11.2 & 10.4 \\
\hline $\begin{array}{l}\text { Transporte e comuni- } \\
\text { cações }\end{array}$ & 4.2 & 1.1 & 5.0 & 1.0 & 4.7 & 1.0 & 5.3 & 1.2 & 5.0 & 0.8 \\
\hline Serviço & 5.8 & 37.2 & 8.1 & 37.2 & 6.3 & 39.6 & 9.7 & 33.6 & 8.9 & 32.1 \\
\hline Atividades Sociais ${ }^{2}$ & 1.1 & 9.7 & 1.7 & 10.8 & 2.3 & 16.3 & 2.7 & 17.9 & 3.2 & 17.1 \\
\hline Administração Pública ${ }^{3}$ & 3.2 & 1.8 & 3.4 & 2.0 & 4.2 & 2.6 & 4.3 & 3.1 & 49 & 3.3 \\
\hline Outros & 1.0 & 0.9 & 2.5 & 2.7 & 3.9 & 3.9 & 4.8 & 6.2 & 6.3 & 5.3 \\
\hline- & 1460979 & 2507564 & 1867316 & 4076861 & 2339177 & 6165447 & 3139298 & 11842726 & 35462932 & 17774004 \\
\hline
\end{tabular}

Fonte: Percentagens computadas através dos dados do Censo: Anuário Estatístico do Brasil. 1985. IBGE, p. 132

${ }^{1}$ Fonte: PNAD, 1985. Volume 9. Tomo 1. IBGE, p. 21.

${ }^{2}$ Inclui os funcionários públicos da rede de educação pública e dos serviços de saúde.

${ }^{3}$ Inclui administração federal, estadual e municipal, justiça, defesa nacional e segurança pública.

${ }_{1}^{175 \%}$ dos professores e $43 \%$ dos trabalhadores da saúde (Censo 1980, Mão-de-obra, p. 33). 
Tabela 2: Empregados na Previdência Social, nos serviços de saúde e educação, por sexo - Brasil (1980)

\begin{tabular}{l|c|c|c}
\hline Serviços sociais públicos & Homens & Mulheres & (\%) Mulheres \\
\hline Previdência social & 50287 & 67808 & 57.4 \\
\hline Serviços médicos & 126825 & 244986 & 65.9 \\
\hline Professores públicos & 192873 & 1047907 & 84.5 \\
\hline
\end{tabular}

Fonte: Dados do Censo. FIBGE. Censo Demográfico - Mão-de-obra. Tabela 1.7. p. 33.

A Tabela 3 mostra que os homens e as mulheres ocupam posições muito diferenciadas na administraçãopública. Os batalhões de professores e trabalhadores em saúde não estão incluídos nesta tabela, onde fica claro que as mulheres estão praticamente excluídas do serviço militar e da polícia, o setor onde estão empregados a maioria dos homens. Também entre os servidores públicos, a participação das mulheres varia bastante, indo de quase zero na construção e na indústria para $38,5 \%$ nas áreas técnicas e científicas. Por sua vez, tal percentagem esconde uma imensa variação dentro desta categoria, onde as mulheres são predominantemente assistentes sociais, bibliotecárias etc., enquanto os homens são engenheiros, contadores e outros profissionais do gênero. Nem mesmo nos "serviços", numa categoria muito mal remunerada, deixa de haver segregação: as mulheres estão nos serviços de limpeza enquanto os homens são porteiros. Apenas entre os trabalhadores de escritório parece haver menor segregação, pois a outra categoria com altas percentagens de mulheres (cargos públicos efetivos, diretores, consultores e gerentes) é bastante heterogênea, estando as mulheres concentradas nos cargos de gerência média e inferior de certas seções.

Isso pode ser visto na Tabela 4. Essa tabela inclui, além dos cargos públicos eletivos, diretores e gerentes já incluídos na Tabela 3, os diretores e gerentes das companhias estatais e os serviços sociais públicos, não classificados pelo Censo como "administração pública". Enquanto as mulheres são uma pequena minoria nas empresas estatais nas áreas da indústria, agricultura, comércio e transporte, são a presença predominante nos serviços sociais. Embora as percentagens nos cargos públicos eletivos que aparecem nessa tabela chegue a $11,3 \%$, a maioria dessas mulheres são provavelmente prefeitas de cidades pequenas ou vereadoras nas câmaras municipais. Como se pode ver pela Tabela 5, as mulheres estão praticamente ausentes dos postos mais elevados, em função de sua participação limitada na política partidária, como apontou Costa (1985).

As diferenças de renda por sexo, de algumas ocupações selecionadas, mostra uma realidade dramática. Enquanto o salário-mínimo no Brasil é absurdamente baixo (US\$ 53.37 dólares por mês pela taxa de câmbio de 16 de fevereiro de 1987), $50 \%$ das mulheres que entram nos setores considerados economicamente ativos 
recebem menos que esse mínimo legal e 50\% dos homens recebem menos do que US\$ 74.72 dólares. Muitas destas são trabalhadoras rurais, mas mesmo as professoras da escola primária ganham menos que o mínimo quando trabalham em pequenos municípios. O Brasil conquistou o vergonhoso destaque de ser o país com a mais desigual distribuição de renda no mundo, e um indicador desta realidade pode ser visto na Tabela 6 , onde se vê a imensa variação do salário médio de algumas ocupações. O que é mais gritante nesta tabela é que os diferenciais entre homens e mulheres são enormes em todos os grupos ocupacionais, exceto nas áreas de defesa nacional e segurança pública, onde o número de mulheres é muito reduzido e elas se encontram em ocupações técnicas. Essas diferenças refletem menos um desrespeito à lei de "salário igual para trabalho igual", e mais as dificuldades encontradas pelas mulheres em relação às oportunidades de carreira. De qualquer forma, para se dizer pouco, é um escândalo que choca mesmo um observador acostumado a analisar a discriminação a que estão sujeitas as mulheres.

Tabela 3: Empregados na Administração Pública, por ocupação e sexo - Brasil (1980)

\begin{tabular}{|c|c|c|c|}
\hline Ocupação & Homens & Mulheres & (\%) Mulheres \\
\hline Cargos eletivos, diretores e gerentes ${ }^{1}$ & 55655 & 20464 & 27.5 \\
\hline Trabalhadores de escritório² & 322401 & 183610 & 36.3 \\
\hline Agentes fiscais & 39690 & 5850 & 12.8 \\
\hline Áreas científicas, técnicas e artísticas ${ }^{3}$ & 116129 & 72131 & 38.5 \\
\hline Juízes, promotores públicos & 15520 & 51,41 & 24.9 \\
\hline Construção e indústria & 125413 & 1924 & 1.5 \\
\hline Transporte e comunicação & 89623 & 4851 & 5.1 \\
\hline Serviços ${ }^{4}$ & 111298 & 54074 & 32.7 \\
\hline Defesa nacional e segurança pública & 486680 & 5185 & 1.1 \\
\hline Outros $^{5}$ & 165775 & 32330 & 16.3 \\
\hline Total & 1353517 & 388767 & 21.4 \\
\hline
\end{tabular}

Fonte: Dados do Censo. FIBGE. Censo Demográfico - Mão-de-obra. Tabela 1.11. pp. 67-98.

${ }^{1}$ Inclui ministros, governadores, prefeitos, legislativo e diplomatas.

${ }^{2}$ Exclui agentes fiscais.

${ }^{3}$ Exclui Juízes e promotores públicos.

${ }^{4}$ Inclui funcionários de limpeza, porteiros etc.

${ }^{5}$ Inclui comércio, agricultura e outros. 
Tabela 4: Diretores e gerentes dos serviços públicos, segundo sexo e setor de atividade - Brasil (1980)

\begin{tabular}{l|c|c|c}
\hline Setor de atividade & Homens & Mulheres & (\%) Mulheres \\
\hline $\begin{array}{l}\text { Ministros, governadores, prefeitos, } \\
\text { legislativo e diplomatas }\end{array}$ & 11067 & 1405 & 11.3 \\
\hline Indústria e agricultura & 2667 & 269 & 9.2 \\
\hline Comércio, transporte e serviços & 833 & 134 & 13.9 \\
\hline Serviços sociais & 12093 & 27993 & 69.8 \\
\hline Administração pública & 42788 & 19059 & 30.8 \\
\hline Outras atividades & 943 & 145 & 13.3 \\
\hline Total: & $\mathbf{7 0 3 8 1}$ & $\mathbf{4 9 0 3 5}$ & $\mathbf{4 1 . 1}$ \\
\hline
\end{tabular}

Fonte: Dados do Censo. FIBGE. Censo Demográfico - Mão-de-obra. Tabela 1.11. pp. 67-98.

Tabela 5: Distribuição de cargos governamentais mais elevados, por sexo Brasil (1975/1986)

\begin{tabular}{l|c|c|c|c|c|c}
\hline \multirow{2}{*}{ Cargo } & \multicolumn{3}{|c|}{1975} & \multicolumn{2}{c}{1986} & \% \\
\cline { 2 - 7 } & Homens & Mulheres & $\begin{array}{c}\% \\
\text { Mulheres }\end{array}$ & Homens & Mulheres & Mulheres \\
\hline Ministros & 21 & 0 & 0.0 & 22 & 0 & 0.0 \\
\hline Justiça Federal & 68 & 0 & 0.0 & 87 & 0 & 0.0 \\
\hline Senadores & 63 & 0 & 0.0 & $69^{\text {a }}$ & $0^{\text {a }}$ & 0.0 \\
\hline Câmara Federal & 363 & 1 & 0.3 & $461^{\text {a }}$ & $26^{\text {a }}$ & 5.3 \\
\hline Embaixadas & 72 & 1 & 1.4 & 88 & 0 & 0.0 \\
\hline $\begin{array}{l}\text { Diretores de } \\
\text { Ministérios (a) }\end{array}$ & 178 & 7 & 5.8 & 345 & 32 & 8.5 \\
\hline Governadores & 21 & 0 & 0.0 & 23 & 1 & 4.2 \\
\hline $\begin{array}{l}\text { Secretários de } \\
\text { Estado }\end{array}$ & 221 & 8 & 2.6 & 358 & 20 & 5.3 \\
\hline
\end{tabular}

Fonte: 1975. Costa (1985) 1986. Autoridades brasileiras, Brasília. Empresa Brasileira de Notícias.

${ }^{1} \mathrm{O}$ crescimento no período se deve à criação de novos postos e à consideração de certos postos em 1986 e não em 1975.

221 não foram incluídos pois seus nomes são neutros.

${ }^{\text {a }}$ O número se refere a 1987.

Em relação aos diferenciais de renda média entre os profissionais do sexo masculino e feminino nos níveis de gerência, a administração pública não está em melhor posição do que o setor privado. A vantagem absoluta que tanto homens como mulheres têm neste campo, quando comparado com o setor privado, se deve ao fato de que aí se inclui uma alta proporção de microempresas onde as responsabilidades de gerenciamento são mínimas. 
Tabela 6: Renda média (em múltiplos de salários mínimos) de grupos ocupacionais selecionados - Brasil (1980)

\begin{tabular}{l|c|c|c|c}
\hline \multirow{2}{*}{\multicolumn{1}{c|}{ Ramo de atividade }} & \multicolumn{2}{c|}{$\begin{array}{c}\text { Número total de } \\
\text { trabalhadores }\end{array}$} & \multicolumn{2}{c}{$\begin{array}{c}\text { Percentagem dos que } \\
\text { contribuem para a } \\
\text { Previdência Social }\end{array}$} \\
\cline { 2 - 5 } & Homens & Mulheres & Homens & Mulheres \\
\hline Setor primário & 11913894 & 3276499 & 8.6 & 1.8 \\
\hline Setor secundário & 9875116 & 2208862 & 71.0 & 70.3 \\
\hline Setor terciário & 13973922 & 12288643 & 68.7 & 50.1 \\
\hline Comércio & 3959635 & 1888028 & 61.1 & 88.2 \\
\hline Transporte e comunicação & 1766730 & 149279 & 78.8 & 90.9 \\
\hline Serviços & 3142549 & 8711610 & 84.8 & 19.7 \\
\hline Atividades sociais (1) & 1118888 & 3032370 & 85.7 & 84.8 \\
\hline Administração Pública (2) & 1784379 & 892387 & 82.7 & 92.3 \\
\hline Outros & 2232071 & 948002 & 76.8 & 79.8 \\
\hline Total: & 38462932 & 17774004 & 49.1 & 43.7 \\
\hline
\end{tabular}

Fonte: Dados do Censo. FIBGE. Censo Demográfico - Mão-de-obra. Tabela 1.9. pp. 47-57

\section{A lei e a realidade}

A Constituição brasileira de 1934 estabeleceu a igualdade salarial entre homens e mulheres, mas quando se estabeleceu o primeiro salário-mínimo em 1940, autorizou-se um salário mais baixo para as mulheres (Verucci e Marino, 1985). A Constituição de 1967, produto do golpe militar, trazia, entretanto, um princípio importante de igualdade nas contratações, reforçado pela Lei 5.473 de 1968, que estabelece a ilegalidade de qualquer ato ou norma que, direta ou indiretamente, seja discriminatório em relação às mulheres na seleção de emprego, tanto nas empresas públicas ou estatais, ou no serviço público, em qualquer nível. Na prática, os efeitos desta e de outras leis deixam muito a desejar, devido à combinação de vários fatores: não há suficiente conhecimento público sobre os direitos legais das mulheres; os sindicatos e os fiscais do governo não dão grande prioridade ao problema da discriminação sexual: a população em geral, e as mulheres em especial, evitam recorrer à justiça, um procedimento em geral caro e moroso; na maioria das vezes, a discriminação assume formas sutis que são dificilmente documentáveis.

Um indicador do baixo nível de consciência que prevalece entre os setores que definem as políticas públicas no país, foi a resposta dada pelo Brasil, em 1979, ao questionário das Nações Unidas, sobre a implementação do Plano de Ação Mundial para a Década da Mulher. Em relação à existência ou não de estratégias globais e mecanismos de ação, afirmou-se simplesmente que não eram necessários uma vez que o status das mulheres na sociedade brasileira estava progredindo "naturalmente". 
Essa noção de "evolução natural" ea complacência com uma situação extremamente desigual em todos os campos têm sido questionadas por um movimento de mulheres em expansão. Esse movimento policlassista teve, na última década, bastante sucesso em trazer a desigualdade de gênero à discussão pública, aos meios de comunicação e aos fóruns políticos, e em criar um novo clima que impulsionou os governos pósautoritários, eleitos a partir de 1982, a criar os "Conselhos dos Direitos da Mulher". Mulheres ativas nos movimentos sociais foram indicadas para estes órgãos estatais, a nível nacional, estadual e municipal, que têm o papel de assessoramento do executivo e implementação de ações que promovam a igualdade para as mulheres.

Esses Conselhos têm apoiado, com bastante sucesso, as reivindicações do movimento de mulheres nas áreas de creche e violência. O número de creches para os filhos de funcionárias da administração pública, embora ainda esteja longe de responder à imensa demanda, tem crescido sistematicamente, como resultado de mobilizações e pressão organizada. Esse serviço é agora considerado um direito das mulheres e das crianças e uma obrigação do Estado (FUSSESP, 1986). Um decreto² recente do presidente da República estabelece que cada repartição federal deve fazer um plano de Atendimento Pré-escolar para os filhos de seus empregados. Embora os critérios de seleção dos beneficiários fiquem em aberto, é em geral dirigido às funcionárias de renda mais baixa, uma vez que as outras funcionárias podem recorrer a berçários e escolas privadas.

Às vésperas da abertura do processo constituinte, desenvolveu-se entre as mulheres um debate nacional sobre os princípios que almejavam consolidar na nova Carta. Em relação às leis trabalhistas e de previdência social, havia um consenso sobre a questão da igualdade no acesso ao emprego e promoções, mas permaneciam algumas controvérsias quanto à redução da idade para aposentadoria para as mulheres, benefícios previdenciários para as donas-de-casa, extensão da licença maternidade e paternidade. Por trás dos itens específicos há um princípio básico em discussão: deve a lei ignorar as desigualdades sociais passadas e as atuais ou deve buscar compensar as perdas acumuladas que vão erodindo as oportunidades das mulheres? Parece que a visão predominante vai em direção à abolição de qualquer tratamento diferenciado, considerado um protecionismo às avessas que acaba tendo efeito contrário. Coerente com esta visão, um dos principais alvos atualmente são as leis da previdência social que não estendem ao esposo da trabalhadora os mesmos benefícios que usufruem as esposas dos segurados. Isso é ainda mais válido para os funcionários públicos, uma vez que sua grande maioria é vinculada ao sistema de previdência social, como se vê pela Tabela 7.

\footnotetext{
210 de outubro, 1986.
} 
Tabela 7: Percentagem de trabalhadores vinculados ao sistema de Previdência Social segundo o sexo e ramo de atividade - Brasil (1985)

\begin{tabular}{|c|c|c|c|c|}
\hline \multirow[t]{2}{*}{ Ramo de atividade } & \multicolumn{2}{|c|}{$\begin{array}{l}\text { Número total de } \\
\text { trabalhadores }\end{array}$} & \multicolumn{2}{|c|}{$\begin{array}{c}\text { Percentagem dos que } \\
\text { contribuem para a } \\
\text { Previdência Social }\end{array}$} \\
\hline & Homens & Mulheres & Homens & Mulheres \\
\hline Setor primário & 11913894 & 3276499 & 8.6 & 1.8 \\
\hline Setor secundário & 9875116 & 2208862 & 71.0 & 70.3 \\
\hline Setor terciário & 13973922 & 12288643 & 68.7 & 50.1 \\
\hline Comércio & 3959635 & 1888028 & 61.1 & 88.2 \\
\hline Transporte e comunicação & 1766730 & 149279 & 78.8 & 90.9 \\
\hline Serviços & 3142549 & 8711610 & 84.8 & 19.7 \\
\hline Atividades sociais (1) & 1118888 & 3032370 & 85.7 & 84.8 \\
\hline Administração Pública (2) & 1784379 & 892387 & 82.7 & 92.3 \\
\hline Outros & 2232071 & 948002 & 76.8 & 79.8 \\
\hline Total: & 38462932 & 17774004 & 49.1 & 43.7 \\
\hline
\end{tabular}

Fonte: Percentagens computadas dos dados do PNAD: PNAD 1985. Volume 9. Tomo 1. p. 21.

(1) Inclui funcionários públicos vinculados à educação pública e serviços de saúde.

(2) Inclui administração federal, estadual e municipal, justiça, defesa nacional e previdência social.

O potencial e os limites das mudanças atuais se refletiram nas eleições de novembro de 1986, quando o número de mulheres na Câmara Federal subiu de 8 para 26. Esse crescimento sem precedentes representa, entretanto, apenas 5,3\% do número de cadeiras. A crise econômica atual impõe outras restrições sérias a futuras vitórias. Imerso em uma imensa dívida, o país, seguindo as orientações do FMI, se afunda em uma profunda recessão no início dos anos 80 . A recuperação no biênio 1985-86 não foi suficiente para restabelecer os níveis anteriores da atividade econômica nem foi direcionada para corrigir as distorções estruturais. Atualmente, o serviço da dívida e as altas taxas de inflação, juntamente com os desequilíbrios estruturais, colocam uma ameaça à estabilidade institucional e às melhorias prometidas aos setores menos privilegiados.

\section{Um estudo de caso}

São raras no Brasil as pesquisas de campo sobre as mulheres na administração pública. Uma exceção interessante foi o trabalho feito por Santos, em 1978, entrevistando 63 profissionais do sexo feminino, empregadas em quatro empresas estatais. Essas mulheres ocupavam postos bastante privilegiados pois estas empresas (duas do setor de energia, uma de mineração e uma de comunicações) se 
enquadram no "setor moderno" da economia e pagam salários bem acima do que é usual nos outros setores do serviço público.

As percentagens de mulheres nos quadros profissionais dessas empresas eram de $4,4 \%, 6,8 \%, 6,8 \%$ e 16,3\%. Mesmo nesta última empresa, a segregação ocupacional significava que menos de $5 \%$ dos engenheiros, contadores, economistas e geólogos eram mulheres. Nos postos de gerência, a percentagem de mulheres é ainda menor, indo de 0,96\% a 8,1\% (Santos, 1982).

A origem familiar das mulheres entrevistadas aponta que uma grande proporção delas vêm de famílias privilegiadas: $54 \%$ de famílias de classe alta e média alta: seus pais são grandes proprietários rurais, homens de negócio ou profissionais bemsucedidos. Apenas $10 \%$ vinham de camadas mais baixas dos trabalhadores urbanos e rurais. Há uma interessante mobilidade entre gerações que pode ser observada na relação entre a situação destas mulheres e a de suas avós (apenas 55\% delas havia trabalhado como assalariadas) e de suas mães (apenas 23\% delas havia participado da força de trabalho e apenas $10 \%$ tinha graduação universitária).

A classe social de origem tem um peso fundamental uma vez que os amigos e parentes acabam jogando um papel crucial no acesso a empregos para muitas destas mulheres. Embora as empresas estatais supostamente partilhem de valores universais e critérios impessoais no preenchimento de suas vagas, não ocorrera assim para pelo menos $47 \%$ das mulheres entrevistadas que, para terem acesso ao emprego, tiveram que acionar sua rede informal de relações. Os concursos abertos e mesmo os métodos mais formais parecem se limitar a funções administrativas e burocráticas.

Alguns depoimentos ilustram os métodos utilizados:

"Quando estava na Universidade, me candidatei para estágio aqui: não fui nem mesmo entrevistada. O homem que estava fazendo o recrutamento me disse: 'Você precisa compreender; mulheres não são aceitas aqui'. Quando me formei, um professor que era um grande amigo meu, e que trabalhava nesta empresa, me perguntou o que pretendia fazer. Respondi-Ihe que ia fazer pós-graduação porque as mulheres aqui não têm qualquer chance. Ao que ele disse: 'Bobagem; me traga o seu curriculum vitae que eu vou dar uma olhada' ".

"Eu me formei em engenharia de comunicações. Passei vários anos fazendo trabalho burocrático. Meus professores trabalhavam aqui e me diziam que a lei permitiria me candidatar mas que eu seria considerada inadequada para o cargo. Minhas colegas mulheres já haviam tentado sem sucesso. Mais tarde, a oportunidade de emprego me foi aberta através de meu marido que conhecia alguém aqui."

"Levei muito tempo para conseguir este emprego. Fui a primeira engenheira aqui. Um amigo meu que trabalhava aqui me marcou um encontro com seu 
patrão. Este - chefe de operações - disse-me que, definitivamente, este não era um emprego para uma mulher, mas que me apresentaria ao chefe de projetos e planejamento. Esse outro chefe me entrevistou duas vezes. Na segunda vez, ele me disse: 'Minha esposa me deu permissão para contratar uma mulher. Além disso, consultei também seus futuros colegas e eles não fizeram objeção'”.

É impressionante a quantidade de casos onde a discriminação aberta ou sutil em relação às mulheres se relaciona implícita ou explicitamente à tentativa de controlar a sexualidade das mulheres ou proteger valores familiares tradicionais. Parece que muitos homens consideram a presença de mulheres entre os colegas de trabalho uma ameaça especial às famílias estabelecidas e ao ego masculino. Ao contrário da aceitação de sua presença em postos subordinados - onde as mulheres são vistas como facilmente disponíveis e prontamente descartáveis - a sua presença em uma situação de igualdade, parece introduzir uma perigosa tonalidade sexual ao ambiente de trabalho supostamente neutro, onde o sexo apenas se insinua desempenhando o papel de uma amenidade adicional.

De qualquer forma, a maioria destas mulheres entrevistadas usaram métodos individualistas para superar estas barreiras. Apenas entre as geólogas houve uma ação organizada coletiva quando uma mulher foi impedida de participar de um exame de seleção em 1975. Os protestos públicos chegaram até o Senado e, depois de uma longa batalha, essa discriminação ilegal foi banida.

\section{Os avanços na carreira}

Santos (1982) aponta duas barreiras principais para os avanços na carreira para as mulheres. Primeiro, a maioria das mulheres por ela entrevistada ocupavam funções de apoio administrativo, muito poucas tinham funções técnicas em atividades finais. As geólogas trabalhavam em laboratórios, as engenheiras em treinamento técnico e daí para frente. Parcialmente, isso se deve ao fato de que as empresas estatais sofrem de um tipo de "inchaço" onde uma boa parte do seu pessoal - tanto homens como mulheres - trabalham em projetos não essenciais, e parcialmente à discriminação em relação às mulheres, justificada por argumentos de que para as mulheres é impraticável viajar, acampar, ser respeitada pelos operários e outros argumentos do gênero. Como diz uma das entrevistadas: "Eles estão sempre preocupados comigo: 'Não mandaremos você viajar pois seu marido não iria gostar'”.

Em segundo lugar as mulheres raramente ascendem aos postos de gerência. Santos (1982) classificou os cargos de gerência em quatro níveis. No primeiro nível (presidentes e diretores) não encontrou nenhuma mulher; no segundo (superintendentes de departamento e diretores de serviços), encontrou uma: no terceiro (chefes de divisões) havia 8 mulheres e no quarto, 6. E aí, novamente, as relações informais desempenham um papel muito importante. Como disse uma 
das entrevistadas: "Os homens se ajustam melhor a alguns tipos de esquemas que, infelizmente, ainda funcionam. O sr. fulano almoça todos os dias com o sr. beltrano, e quando um sobe, puxa o outro".

É interessante notar que o casamento também funciona como um multiplicador de relações sociais, o que implica que as mulheres casadas ocupam postos mais elevados, mesmo tendo menor tempo de empresa. Entre as 8 mulheres que estavam no terceiro nível, 5 eram casadas com funcionários que estavam em postos mais altos na mesma empresa ou em empresa do mesmo tipo ${ }^{3}$. Santos acredita que isso não se deve ao nepotismo, mas ao fato de que, através de seus maridos, conseguem ter acesso a uma rede informal de relações onde a sua competência fica visível, e podem adotar o estilo de comportamento e comunicação que faz parte da cultura masculina.

O casamento, entretanto, pode ser uma faca de dois gumes. Uma das entrevistadas relata: "A prioridade é dada aos homens; e no meu caso é ainda pior pois o meu marido trabalha na mesma empresa. Eles brincam que eu não preciso ser promovida porque meu marido já está nos escalões superiores. Eu respondo a essa brincadeira dizendo que eu não preciso trabalhar 8 horas por dia porque ele trabalha por mim". E se espera, de fato, que as mulheres aceitem esses critérios. Uma outra entrevistada conta como o seu chefe tentou fazê-la compreender porque estava promovendo o seu colega do sexo masculino, ao invés dela: "Porque a esposa dele não trabalha e o seu marido tem um bom salário".

A moral sexual é, novamente, um outro fator que entrava a ascensão profissional das mulheres. Há um testemunho que não deixa dúvidas a respeito: "Se eu a promovesse - disse o meu supervisor - eu teria que viajar com você, e sei que minha esposa não gostaria da idéia".

Os obstáculos que dificultam o acesso das mulheres aos cargos de gerência são internalizados por elas próprias que, sabendo que suas chances são pequenas, rebaixam suas expectativas e vêem as funções gerenciais como duras, desumanas, competitivas demais, incompatíveis com a natureza feminina. A divisão sexual do trabalho na família se reproduz na empresa, onde as mulheres acham mais fácil se colocar em uma função sendo dirigidas por um homem. Várias mulheres declararam que preferiam ser assistentes do que controlar pessoal ou serem chefes. Algumas mulheres que rompem com esse padrão se sentem bastante desconfortáveis: "Eu nunca temia discordar, expressar minha opinião. Sempre fui uma líder na escola e na empresa. Nunca temi responsabilidades. Nem mesmo brigar. Mas o preço é muito alto. Sinto-me sozinha e diferente; e isso é muito desagradável. Às vezes prefereriria ser como é uma mulher comum no contexto de nossa sociedade".

\footnotetext{
${ }^{3}$ Das 63 mulheres entrevistadas, 31 eram casadas. Destas, 13 tinham a mesma profissão do marido; em 11 casos o marido trabalhava na mesma empresa; e em 7 trabalhavam em empresas do mesmo tipo.
} 
Esse conflito que é percebido, entre seu papel tradicional e sua identidade como mulheres, raramente encontra uma solução adequada, principalmente porque as condições objetivas em casa não mudaram muito. O trabalho doméstico continua uma responsabilidade feminina, que não é compartilhada pelos maridos, mesmo quando seu salário é mais alto do que o dele. Muitas delas contam com o apoio de outras mulheres: enfermeiras, empregadas, cozinheiras (facilmente pagas com uma pequena fração de seus altos salários) ou de parentes: mas em uma situação de crise são elas que precisam deixar o emprego para tomar conta dos filhos.

Ao mesmo tempo, a fim de serem respeitadas como profissionais, sentem necessidade de construir uma barreira entre os dois mundos: "Sempre tive o maior cuidado de evitar que as pessoas invadissem minha privacidade, que percebessem meus problemas fora do serviço. Porque se ficassem sabendo, os usariam para me castrar... Se você disser a alguém que não conseguiu dormir porque seu filho teve febre e você não trabalha bem naquele dia, vão dizer que a culpa é desses problemas de mulher".

As crianças são, em realidade, uma ameaça a essa tênue fronteira entre os dois mundos. $E$ algumas mulheres consideram que elas deveriam ser mantidas à distância deste mundo de forma a não atrapalhar a imagem de uma profissional altamente dedicada: "Quando tiver filho, vou colocá-lo na creche. A empresa devia ter serviço de creche. Mas não no mesmo prédio. (Seria horrível. No final do dia, ia parecer uma fábrica.) Bem, pode até ser que fosse aqui. A gente entraria com as crianças por uma portinha nos fundos".

Pode ser que hoje, quase dez anos mais tarde, a influência das idéias feministas tenham mudado um pouco a percepção destas mulheres, mas já em 1978, duas delas ainda diziam orgulhosamente: "Converso com meus colegas de igual para igual: de homem para homem" e "O melhor cumprimento que recebi do meu supervisor foi que ele me considerava como um homem".

Ecomo estas mulheres jamais serão homens, a sua aceitação sem questionamentos da organização doméstica existente e as políticas da empresa que ignoram os compromissos familiares de seus funcionários se combinam para criar junto a elas uma ambivalência psicológica que mina constantemente seus esforços profissionais. 


\section{Referências}

BAeR, Werner, Kerstenetzky, Issac \& VillelA, Anibal. 1973. As modificações no papel do Estado na economia brasileira. Pesquisa e Planejamento Econômico 3(4): 883-912. COSTA, Albertina G.O. 1985. Política governamental e a mulher. Editora Nobel, Conselho Estadual da Condição Feminina, São Paulo.

FUSSESP. 1986. Relatório do Programa Centro de Convivência Infantil. Fundo Social de Solidariedade do Estado de São Paulo.

GIfFIN, Karen. 1979. Opportunities and Ideologies: Women in High Status Professions in Bahia, Brazil. PhD Dissertation. University of Toronto.

GouvelA, Aparecida J. 1972. O emprego público e o diploma de Curso Superior. Fundação Carlos Chagas, São Paulo.

HAHNER, June. 1981. A mulher brasileira e suas lutas sociais e políticas: 1850-1937. Ed. Brasiliense, São Paulo.

MARTINS, Carlos Estevam. 1974. Tecnocracia e Capitalismo - a política dos técnicos no Brasil. Brasiliense, São Paulo.

SANTOS, Selene S.C.H. 1982. A mulher de formação universitária em algumas empresas estatais in Bruschini, C. e Rosemberg, F. (ed.) Trabalhadoras do Brasil. Editora Brasiliense. São Paulo.

VerucCl, Floriza \& MARINo, Ediva. 1985. Os direitos da mulher. Editora Nobel. Conselho Estadual da Condição Feminina, São Paulo.

VIEIRA DA CUNHA, Mario W. 963. O sistema administrativo brasileiro 1930-1950. Centro Brasileiro de Pesquisas Educacionais. Rio de Janeiro.

\section{Carmen Lúcia de Melo Barroso}

Doutora em Psicologia Social pela Universidade de Colúmbia (Nova lorque), pesquisadora visitante da Universidade de Cornell (Nova lorque) e professora do Macalester College (Minnesota), nos Estados Unidos. Na década de 80, período em que o texto foi escrito, a autora atuava como pesquisadora da Fundação Carlos Chagas, era Professora da PUC de São Paulo e do Departamento de Ciências Sociais da USP, além de ser conselheira do Conselho Nacional dos Direitos da Mulher e presidente da Comissão Nacional de Saúde Reprodutiva do Ministério da Saúde. Em 1989, Carmen Barroso foi convidada para dirigir o Departamento de Políticas de População e Saúde Reprodutiva da Fundação MacArthur em Chicago, onde permaneceu até 2003. Desde então ela é Diretora do Hemisfério Ocidental da International Planned Parenthood Federation (IPPF), residindo em Nova York. Sob sua direção, a IPPF passou a atuar em todos os países das Américas e em grande parte dos países do Caribe, promovendo os direitos sexuais e os direitos reprodutivos. Atualmente, a autora tem atuação destacada no Independent Expert Review Group (IERG) criado pelo Secretário Geral da ONU, Ban Ki-moon, em 2011, para monitorar a Estratégia Global de Saúde da Mulher e da Criança, cujos relatórios anuais são apresentados por ocasião da Assembleia Geral da ONU. Ela também faz parte do Independent Expert Advisory Group on Data Revolution for Sustainable Development (IEAG), sendo nomeada em 2014. Por sua dedicação ao tema, Carmen Barroso tem recebido destacados reconhecimentos públicos, tendo sido recentemente nomeada uma das 21 mulheres líderes do século XXI, pela Women's eNews. 
